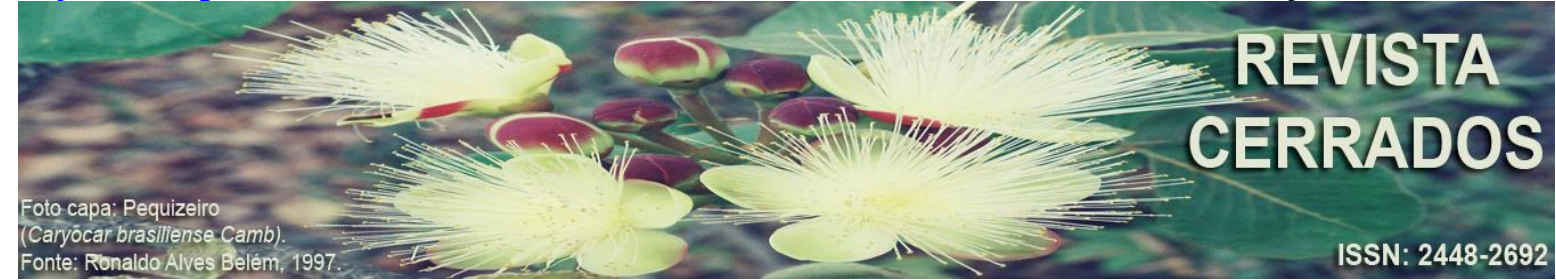

\title{
A IMPORTÂNCIA DO TERRITÓRIO EM AÇÕES DE VIGILÂNCIA EM
} SAÚDE

\section{THE ROLE OF TERRITORY IN THE ACTIONS OF HEALTH SURVEILLANCE}

\section{LA IMPORTANCIA DEL TERRITORIO EN LAS ACCIONES DE VIGILANCIA DE LA SALUD}

\author{
Aline Fernanda Cardoso \\ Universidade Estadual de Montes Claros - Unimontes, Montes Claros, Minas \\ Gerais, Brasil \\ E-mail: <alinecardoso1@ outlook.com.br>. \\ Valéria Aparecida Moreira Costa \\ Universidade Estadual de Montes Claros - Unimontes, Montes Claros, Minas \\ Gerais, Brasil \\ E-mail: <valeriamoreirs@gmail.com>. \\ Cássio Alexandre da Silva \\ Universidade Estadual de Montes Claros - Unimontes, Montes Claros, Minas \\ Gerais, Brasil \\ E-mail: <cassioas27@gmail.com>.
}

\section{RESUMO}

As condições de vida das pessoas e suas interações com meio econômico, social e territorial estão intimamente ligadas ao risco e consequentemente ao processo saúde-doença. $\mathrm{O}$ conhecimento da dinâmica social em determinado território, os hábitos e costumes é de fundamental relevância para determinar as vulnerabilidades para a saúde. O objetivo deste trabalho é discutir a importância dos estudos de territórios como estratégia em ações de vigilância em saúde. A metodologia constituiu em revisão bibliográfica sobre a categoria em foco, autores como (RAFFESTIN, 1993), (HAESBAERT, 2004), (ALMEIDA, 2010), (SANTOS, 2003), e pesquisa documental em órgãos públicos como o Ministério da Saúde MS. Conclui-se que o território torna-se uma estratégia de gestão essencial para ações em vigilância, e subsídio para as políticas de saúde que devem fundamentar-se nas particularidades dos processos territoriais, considerando que apenas os aspectos biológicos não são suficientes para a organização do sistema de atenção à saúde que atenda com eficácia as especificidades da população. 
CARDOSO, A. F.; COSTA, V. A. M.; SILVA, C. A.

A importância do território em ações de vigilância em saúde

Palavras-chave: Saúde. Território. Vigilância.

\begin{abstract}
The living conditions of people and their interactions with economic, social and territorial environment are closely linked to the health-disease process and its risks. Knowledge of social dynamics, habits and customs in a given territory, is of fundamental relevance to determine health vulnerabilities. The purpose of this paper is to discuss the importance of territorial studies as a strategy to deal with health surveillance actions. The methodology consisted of a bibliographic review analyzing authors such as (RAFFESTIN, 1993), (HAESBAERT, 2004), (ALMEIDA, 2010), (SANTOS, 2003), and documentary research in public agencies such as the Ministry of Health - MH. We concluded that the territory is an essential management strategy for actions in surveillance, and the subsidy for health policies that must be based on the particularities of the territorial processes, considering that only the biological aspects are not enough for the organization of the health care system that effectively meets the specificities of the population.
\end{abstract}

Keywords: Health. Surveillance. Territory.

\title{
RESUMEN
}

Las condiciones de vida de las personas y sus interacciones con el entorno económico, social y territorial están estrechamente relacionadas con el riesgo y, en consecuencia, con el proceso de salud-enfermedad. El conocimiento de la dinámica social en un territorio, hábitos y costumbres dados es de fundamental importancia para determinar las vulnerabilidades para la salud. El objetivo de este documento es discutir la importancia de los estudios territoriales como estrategia en las acciones de vigilancia de la salud. La metodología consistió en una revisión de la literatura sobre la categoría en foco, autores como (RAFFESTIN, 1993), (HAESBAERT, 2004), (ALMEIDA, 2010), (SANTOS, 2003) e investigación documental en agencias públicas como el Ministerio de Salud - MS Se concluye que el territorio se convierte en una estrategia de gestión esencial para las acciones de vigilancia y subsidio a las políticas de salud que deben basarse en las particularidades de los procesos territoriales, considerando que solo los aspectos biológicos no son suficientes para la organización de la salud. sistema de atención médica que cumple efectivamente con las especificidades de la población.

Palabras clave: Salud. Territorio. Vigilancia.

\section{INTRODUÇÃO}

A identificação das condições de saúde existentes no território é um dos objetivos fundamentais da atenção primária em saúde. A instituição de ações que busquem a prevenção de riscos, bem como a adoção de ferramentas capazes de reduzir a exposição dos indivíduos 
são estratégias no planejamento territorial e execução de ações articuladas em proteção, promoção e recuperação da saúde.

Uma das propostas do sistema de saúde ocorre na adoção de vigilância como método "[...] de organização e funcionamento dos serviços de saúde, e até a participação permanente de ações sociais como uma prática constante de estruturação dos processos de trabalho e de enfrentamento contínuo dos problemas de um determinado território" (SILVA, 2008 p. 36). A criação de programas nos diversos níveis de atendimento a saúde, são definidos a partir da manifestação de fatores epidemiológicos e ambientais, aliados às condições sociais e econômicas para definir o serviço de saúde necessário a este território, desencadeando o fortalecimento e diminuição dos gastos em saúde.

A vigilância é uma das práticas voltadas para a saúde coletiva, onde se considera sua atuação em uma delimitação espacial previamente determinada: o território, que proporciona exatidão administrativa para a gestão física dos serviços de saúde e exprime o perfil ambiental, epidemiológico, socioeconômico e cultural, características que são indispensáveis para a criação de políticas públicas.

O território reflete as diversas dimensões do poder, bem como as relações que são estabelecidas no espaço, o que repercutem a multidimensionalidade do vivido pelos membros da coletividade reproduzindo-se na territorialidade, (RAFFESTIN, 1993). Através do conhecimento do modo de vida da população é possível identificar as enfermidades mais recorrentes, bem como o acesso e as repercussões nos serviços de saúde. Oportuniza "o desenvolvimento de um vínculo entre os serviços de saúde e a população, mediante práticas de saúde orientadas por categorias de análise de cunho geográfico" (MONKEN, 2005; BARCELOS, 2005, p. 899). O objetivo deste trabalho é discutir a importância dos estudos em território como estratégia em ações de vigilância em saúde.

A metodologia constituiu em revisão bibliográfica sobre a categoria território, autores como (RAFFESTIN, 1993), (HAESBAERT, 2004), (ALMEIDA, 2010), (SANTOS, 2003), (RATZEL, 1990) e pesquisa documental em órgãos públicos como o Ministério da Saúde - MS. Esta pesquisa se estrutura em primeiramente refletir o conceito de território propostos por diversos autores, que discutem esta categoria além das delimitações de poder, e sim como uma totalidade complexa que revela interesses de diferentes agentes sociais e políticos que ao reproduzirem o espaço constroem a história e as particularidades culturais. E são estes interesses e interações que configuram a necessidade do ordenamento. A abordagem 
CARDOSO, A. F.; COSTA, V. A. M.; SILVA, C. A.

A importância do território em ações de vigilância em saúde

do território enquanto ferramenta de gestão leva a um dos focos deste trabalho: a territorialização da saúde, implantada pelo Sistema Único de Saúde - SUS, que delimita territórios administrativos e se propõem a compreender as condições de vida e saúde da população, como também a adoção de práticas “[...] capazes de responder com resolutividade — equidade e integralidade de ações — às necessidades e aos problemas de saúde de cada área delimitada" (GODIM et. al. 2008 p. 240).

Relacionada às condições de acesso e qualidade da saúde pública, a segunda parte deste trabalho trata a vigilância em saúde integrada ao território, impulsionado pelas ações e políticas propostas pelo SUS, abarca o controle de riscos, prevenção e agravos de doenças, vulnerabilidades sociais, e promoção da saúde. Reflete também o papel das municipalidades em incluir as ações de vigilância em seu cotidiano, seja no planejamento de gestão junto aos atendimentos primários de saúde da família, quanto na conscientização da população para também atuarem como agentes de vigilância.

\section{TERRITÓRIO E TERRITORIALIZAÇÃO EM SAÚDE}

A abordagem em território tem sido alvo constante em pesquisas, principalmente nas últimas décadas, sendo considerado por diversos autores o "conceito da moda". Etimologicamente a categoria território tem origem do latim (territorium) que deriva do vocábulo latino "terra", significa uma parcela de terra apropriada e administrada politicamente. Todavia, o território não é concebido de forma consensual entre todos os pesquisadores que trabalham com essa categoria de análise. Várias concepções são estabelecidas de acordo com as influências históricas vinculadas a diferentes correntes de pensamento (SILVA, 2015).

$\mathrm{Na}$ Geografia, ela emerge a partir dos avanços da proposta de Ratzel (1990) que apresenta o debate territorial para a ciência. Para o referido autor, o território foi entendido como o solo, e a população era substrato do qual se organizava e evoluía a sociedade, como aponta:

Não é possível conceber um Estado sem território e sem fronteiras (...) assim também a sociedade mais simples só pode ser concebida junto com o território que lhe pertence. $\mathrm{O}$ fato de estes dois organismos estarem ligados ao seu solo é a consequência natural da ligação evidente que une a criatura humana a Terra (RATZEL, 1990, p.73). 
CARDOSO, A. F.; COSTA, V. A. M.; SILVA, C. A.

A importância do território em ações de vigilância em saúde

O território que solidifica o Estado, tanto em relação à vivência humana como ao incremento do poder, reforçando a compreensão de que é o território que permite a existência e manutenção de um Estado. Desta forma, Ratzel propunha o território como uma parcela da superfície terrestre apropriada por um grupo humano que utilizaria o território e seus recursos naturais para seu povoamento. O território passa ser indispensável para qualquer população e Estado para evoluir (LIMA, et. al. FORNO, 2014).

Tudo isso "[...] revela a força do poder estatal que, apropriando-se de uma área (espaço), ainda é capaz de se sobrepor a outros poderes dispersos pela sociedade, ampliando seu domínio ao mesmo tempo em que estabelece suas fronteiras" (STÜRMER; COSTA, 2017). Com o predomínio do entendimento de que o território resultava da força e poder do Estado como ator principal, o geógrafo Claude Raffestin (1993) fez um importante contraponto ao tratar das contradições existentes no processo da apropriação do território, e dos múltiplos poderes que materializavam nestas áreas.

Para Raffestin (1993) é essencial compreender bem o espaço que antecede ao território, ambos não devem ser desarticulados, já que o espaço é a "prisão original”, e o território a que os homens constroem para si, ou seja, o território pode ser entendido como produto das relações sociais que se estabelecem no espaço (RAFFESTIN, 1993). Assim sendo:

O espaço é, portanto anterior, preexistente a qualquer ação. O espaço é de certa forma, "dado" como se fosse uma matéria-prima. Preexiste a qualquer ação. "Local" de possibilidades é a realidade material preexistente a qualquer conhecimento e a qualquer prática dos quais será o objeto a partir do momento em que um ator manifeste a intenção de dele se apoderar. Evidentemente, o território se apóia no espaço, mas não é o espaço. (RAFFESTIN, 1993, p. 143 -144).

A formação do território parte do processo de fragmentação do espaço. Os indivíduos buscam construir seus próprios espaços e territórios para garantir sua existência e relações sociais. $\mathrm{O}$ autor destaca as relações de poder existentes no território, como também os processos humanos exercidos individuais ou em grupo. Isto contribui, de certa maneira, conforme Santos destaca, que o território é o "chão mais a população, isto é, uma identidade, o fato e o sentimento de pertencer àquilo que nos pertence... é a base do trabalho, das trocas materiais e espirituais e da vida" (SANTOS, 2003, p. 96).

Raffestin (1993) aponta que a territorialidade parte do pressuposto das relações, sendo definida como o conjunto de trocas que se originam de forma tridimensional por meio 
CARDOSO, A. F.; COSTA, V. A. M.; SILVA, C. A.

A importância do território em ações de vigilância em saúde

da sociedade - espaço - tempo. Já Robert Sack (1986) influenciado pela "Geografia do Poder" de Raffestin aponta a territorialidade como estratégia de controle, isto é, “[...] a tentativa de um indivíduo ou grupo para afetar, influenciar ou controlar pessoas, fenômenos e relações, e para delimitar e impor controle sobre uma área geográfica” (Sack, 1986, p. 19) em suas diversas escalas (das relações espaciais de uma pequena residência às de países) para a variação temporal (territórios diferenciados em partes diferentes de um dia) (ITABORAHY, 2010).

Outros autores já abordam o território de modo mais subjetivo, através da corrente fenomenológica, pautado nos aspectos peculiares à cultura de um povo. Os estudos apontam como um grupo social modela a dimensão territorial por meio de suas relações impregnadas de significados e simbolismos. Destaca-se nesta perspectiva o fortalecimento dos laços identitários, ou seja, o caráter de sociabilidade do território (LIMA, et. al. FORNO, 2014). Nesse sentido, Haesbaert (2004) aponta:

\begin{abstract}
Desde a origem, o território nasce com uma dupla conotação, material e simbólica, pois etimologicamente aparece tão próximo de terra-territorium quanto de terreoterritor (terror, aterrorizar), ou seja, tem a ver com dominação (jurídico-política) da terra e com a inspiração do terror, do medo - especialmente para aqueles que, com esta dominação, ficam alijados da terra, ou no "territorium" são impedidos de entrar. Ao mesmo tempo, por extensão, podemos dizer que, para aqueles que têm o privilégio de usufruí-lo, o território inspira a identificação (positiva) e a efetiva "apropriação" (HAESBAERT, 2004, p. 6774).
\end{abstract}

O território torna-se, uma representação de múltiplas manifestações em determinada área, tanto sociais, naturais, políticas e culturais, este último, dentro um plano simbólico. Portanto, a dimensão material está intimamente ligada com a as representações humanas contidas no território (SILVA, 2015). Assim, todo território tem ao mesmo tempo funções simbólicas como funcionais, pois;

[...] a ocupação do território é vista como algo gerador de raízes e identidade: um grupo não pode mais ser compreendido sem o seu território, no sentido de que a identidade sócio-cultural das pessoas estaria inarredavelmente ligada aos atributos do espaço concreto... E mais: os limites do território não seriam, é bem verdade, imutáveis - pois as fronteiras podem ser alteradas, comumente pela força bruta mas cada espaço seria, enquanto território, território durante todo o tempo, pois apenas a durabilidade poderia, é claro, ser geradora de identidade sócio-espacial, identidade na verdade não apenas com o espaço físico, concreto, mas com o território (SOUZA, 2006, p. 84). 
CARDOSO, A. F.; COSTA, V. A. M.; SILVA, C. A.

A importância do território em ações de vigilância em saúde

Para Almeida (2010) a categoria território nada mais é que o resultado da apropriação econômica, ideológica e sociológica do espaço por grupos que nele imprimem sua cultura e sua história. O sentimento de pertencimento, vinculado com a identidade, produz o território, fruto da vivência, experiência e o uso que os sujeitos lançam sobre o mesmo. Trata-se da compreensão do território-lugar, que;

[...] é uma das formas para compreender e explicar as relações de poder, as identidades, os pertencimentos, as diferenças etc. (...). O território-lugar constitui-se numa relação espaço-tempo em que o povo vive, sente, percebe, aspira, sofre, interage (social, espiritual e naturalmente), coopera, disputa, luta, resiste, degrada, preserva, é extorquido, explorado e subordinado (SAQUET, 2014, p. 27).

Dematteis (2008, p.34) concorda ao afirmar que o território não é somente a superfície das ações do sujeito, parte da produção de relações intersubjetivas que são o "meio e a matriz de um futuro, visando à proteção do conjunto de condições necessárias à vida". Assim, aumenta o interesse pelo território na saúde, do qual todas as ações públicas que visem melhorias nas condições de vida da população sejam elas políticas, econômicas ou sociais, devem levar em consideração o modo de produção vivido, bem como seu aspecto processual de formação do território. O entendimento do processo histórico de qualquer fenômeno, bem como a interação dos grupos sociais, cultura, modo de vida, a própria territorialidade é fundamental para compreender os processos que os tornam vulneráveis a baixa qualidade de vida. O estabelecimento da base territorial em saúde, embora recente tendo a implantação do Sistema Único de Saúde - SUS como marco, proporcionou estudos sobre funcionamento dos serviços de saúde emaranhado no território, buscando "[...] a caracterização da população e de seus problemas de saúde, bem como para avaliação do impacto dos serviços sobre os níveis de saúde dessa população" (MEDONÇA; ARAÚJO; FOGAÇA, 2014, p. 47).

$$
\mathrm{O} \text { uso dessa categoria norteia principalmente as análises que se referem à }
$$
distribuição e serviços ofertados pelos núcleos de saúde, a atuação de cada unidade de saúde nas suas esferas administrativas e a abrangência do recorte territorial de área. A esse respeito Guimarães ressalta que;

A expansão físico-territorial dos serviços de saúde e da cobertura dos principais programas de saúde pública pelos municípios brasileiros, desde a implantação do Sistema Único de Saúde (SUS) no país, demanda a análise dos desafios operacionais da territorialização da política nacional de saúde. Nesse sentido, ganha ênfase o espaço sob controle da ordem administrativa, nos diversos níveis de poder (município, estado e união) [...] (GUIMARÃES, 2014, p.86). 
CARDOSO, A. F.; COSTA, V. A. M.; SILVA, C. A.

A importância do território em ações de vigilância em saúde

A nova abordagem implica na compreensão dos diversos segmentos dos serviços de saúde, principalmente no planejamento das práticas de vigilância e atenção à saúde, através de uma delimitação territorial, sendo possível verificar uma visão integradora que se baseia na acessibilidade e condições de vida da população, podendo ser analisado sobre vários enfoques, como;

[...] o geográfico, que refere-se à distância a ser percorrida para chegar até o serviço, relacionada à disponibilidade de meios de transporte e barreiras geográficas existentes nos percursos (vias de fluxo, ruas não asfaltadas, trevos, aclives ou declives e outros). Também o enfoque funcional: a qualidade dos serviços de saúde oferecidos à população. O enfoque cultural: valorização dos costumes da população dentro desse contexto (PEREHOUSKEI; BENADUCE, 2007, p. 40).

Essa visão propõe identificar e avaliar populações que se encontram em situação de risco, ou seja, encontram-se expostas a uma situação de vulnerabilidade de diferentes conjunturas, buscando contribuir com o planejamento de um recorte territorial de área de abrangência coerente com a realidade vivida pela população, tentando minimizar os aspectos que funcionam como barreiras de acessibilidade aos serviços de saúde.

Torna-se, portanto, evidente a necessidade de estudos sobre o território de saúde pública, compreendido como um local em permanente modificação, que irá atender as relações sociais existentes. Os serviços de saúde devem estar em constante dinamismo, assim como as ações de prevenção e tratamento de doenças. A apreensão das variáveis aplicadas aos territórios especialmente no setor de saúde é imprescindível para a compreensão do contexto vivido da população, principalmente em locais com poucos recursos que merecem maior atenção do Estado.

\section{VIGILÂNCIA EM SAÚDE INTEGRADA AO TERRITÓRIO}

A natureza dos problemas de saúde e os modos de enfrentá-los decorrem das condições políticas, econômicas e sociais de cada tempo e espaço. Assim, se mantém a definição e prática de Vigilância em Saúde que evoluiu de acordo como as ações de saúde públicas desenvolvidas para controlar as doenças (THACKER; BERKELMAN, 1998). No Brasil, antes da criação do Sistema Único de Saúde (SUS) em 1988, as ações de vigilância eram de cunho epidemiológico e sanitário, restritas ao controle de doenças transmissíveis, 
CARDOSO, A. F.; COSTA, V. A. M.; SILVA, C. A.

A importância do território em ações de vigilância em saúde

conduzidas pelo Ministério da Saúde. Enquanto as ações de vigilância ambiental eram praticamente inexistentes no âmbito do sistema público de saúde (BRASIL, 2009).

A descentralização das ações de vigilância epidemiológica para as demais ramificações hoje conhecidas iniciou-se em dezembro de 1999, através da publicação da portaria ministerial 1.399 que regulamentou a Norma Operacional Básica 01/96 quanto às competências da União, estados e municípios na área de epidemiologia e controle de doenças, resultante de debates nas instâncias de pactuação dos intergestores do SUS (BRASIL, 2009).

Em 2004, a portaria ministerial 1.172 publica um novo documento de aprimoramento do processo de descentralização das ações de vigilância. Definem-se as atividades respectivas de vigilância em saúde, em: vigilância de doenças transmissíveis, vigilância de doenças e agravos não transmissíveis e de seus fatores de risco, vigilância ambiental em saúde e vigilância da situação de saúde. Ressalta-se que em algumas unidades da federação e seus respectivos municípios incorporaram a vigilância sanitária e a vigilância à saúde do trabalhador como atividades precípuas da vigilância em saúde (BRASIL, 2009). Tais documentos inferiram as ações de vigilância em saúde como,

[...] um processo contínuo e sistemático de coleta, consolidação, análise e disseminação de dados sobre eventos relacionados à saúde, visando o planejamento e a implementação de medidas de saúde pública para a proteção da saúde da população, a prevenção e controle de riscos, agravos e doenças, bem como para a promoção da saúde (MS, 2013, p. 2).

Para Arreaza e Moraes (2010), a reorganização do setor saúde em face dos princípios de universalização, integralidade e equidade, incitou a epidemiologia a ampliar os horizontes e diagnosticar várias questões que emergiram com a construção do SUS, como o enfrentamento de doenças causadas pela exclusão social e a pobreza gerada pelo processo iníquo de urbanização e industrialização em nosso país. Além disso, proporcionou a reorientação dos serviços de saúde em direção à superação de desigualdades de cobertura, ao acesso equitativo, bem como a oferta organizada e de qualidade ampliada na humanização do sistema nacional de saúde.

Ademais, o processo de “[...] aprimoramento da organização e da gestão do SUS, foram instituídas as Regiões de Saúde, que devem conter, no mínimo, ações e serviços de atenção primária, urgência e emergência, atenção psicossocial, atenção ambulatorial especializada e hospitalar" (NETO et. al., 2017 p. 3138), como também a Vigilância em 
CARDOSO, A. F.; COSTA, V. A. M.; SILVA, C. A.

A importância do território em ações de vigilância em saúde

Saúde. Todas as aberturas no SUS se devem em sua maioria ao reconhecimento de uma base territorial, onde a distribuição dos serviços siga uma lógica de delimitação de áreas de abrangência (BRASIL, 2009). Uma vez que tal método proporciona;

[...] coleta sistemática de dados que vão informar sobre situações-problemas e necessidades em saúde de uma dada população de um território específico, indicando suas inter-relações espaciais. Possibilita ainda, identificar vulnerabilidades, populações expostas e a seleção de problemas prioritários para as intervenções. $\mathrm{O}$ uso da epidemiologia como ferramenta poderosa para $\mathrm{o}$ planejamento através da microlocalização dos problemas de saúde permite a escolha de ações mais adequadas, apontando estratégias e atores que foram identificados no processo de diagnóstico, para melhor as operacionalizarem e viabilizarem no território (GONDIM et. al., GRACIE, 2008, p. 15).

O território em vigilância, não se constitui como um local delimitado geograficamente, e sim como um espaço onde as pessoas vivem e se reproduzem, estabelece suas relações sociais, trabalham e cultivam sua cultura (BRASIL, 2009). Partindo deste pressuposto, o trabalho pautado em ações de "território saúde" deve diminuir os agravos, e contribuir na compreensão das vulnerabilidades e dos riscos em determinado grupo social.

Para Castellanos (1990), o entendimento dos problemas que estruturam uma situação de saúde parte do ponto de vista do ator social, uma vez que os fenômenos de saúde e doença ocorrem em diferentes dimensões, tanto singulares, entre indivíduos ou entre agrupamentos de população, e por atributos gerais, que são os fluxos e fatos que correspondem à sociedade em seu território. Por isso a importância do contato permanente dos representantes dos órgãos públicos de saúde com os grupos sociais e moradores, na busca do desenvolvimento de ações intersetoriais, que visem à participação de todos. Já que esse contanto irá aproximar ambas as esferas, proporcionando o conhecimento do vivido pela população e consequentemente melhorias na qualidade de vida. Como aponta:

Entende-se que os lugares e sua constituição territorial tornam-se vitais para assegurar a fixidez subjacente às instituições. A conduta humana nesses contextos é reproduzida mediante atividades humanas recursivas, continuamente recriadas pelas pessoas através dos próprios meios pelos quais elas se expressam. Em outras palavras, a vida social ostenta uma repetitividade essencial, passível, assim, de aproximações metodológicas para seu entendimento (MONKEN; BARCELOS, 2005 p. 903).

Considerar a constituição territorial de vivência, ou seja, os processos que influenciam e modelam o cotidiano dos grupos sociais deve ser o ponto de partida para as ações de vigilância, uma vez que o mapeamento dos percursos e fluxos diários, interações 
com os demais espaços, é fundamental para entender a base das necessidades e os problemas de saúde das populações. A concepção da vigilância em saúde em articulações participativas, isto é, quando a equipe de saúde e representantes da população busca maneiras de enfrentar a situação - problema de maneira conjunta, exerce um dos princípios fundamentais presentes na concepção da atenção básica: a responsabilidade sanitária e a participação social (BRASIL, 2009).

As ações de vigilância no território esboçam o interesse de diagnósticos mais precisos da vulnerabilidade, isto é a relação dos condicionantes com os determinantes sociais. Para alguns grupos o risco é eminente, a exemplo as populações negras, quilombolas, indígenas, moradores de rua, imigrantes, homossexuais, que passam por situações de violência e discriminação na sociedade, suscetibilidades ou predisposições, tornando-se propensas a apresentar sintomas e doenças. A interpretação da vulnerabilidade deve incorporar o contexto como o lócus, como apontamentos sobre a maior ou menor disponibilidade de recursos de todas as ordens para proteção das pessoas contra as enfermidades em seu território (CONASS, 2015).

As referidas ações de vigilância devem estar inseridas no cotidiano das equipes de saúde dos municípios, principalmente de atenção primária e Saúde da Família por ter contato direto com o indivíduo, proporcionando atividades de promoção da saúde voltadas para a redução da vulnerabilidade e das desigualdades existentes, buscando intervir sobre os determinantes e condicionantes da saúde.

Grande parte dos municípios ainda desenvolve ações de vigilância em saúde de modo centralizado, ou seja, “[...] sem a devida capilaridade para as unidades básicas, o que provoca restrições no efetivo controle das doenças e agravos prioritários e torna distante a possibilidade de operacionalizar o princípio da integralidade da atenção" (BRASIL, 2009, p. 2). Recktenwaldt e Junges (2017) apontam que este cenário se deve pela falta de recursos, já que grande maioria dos municípios brasileiros terem menos de 20 mil habitantes, e os recursos financeiros repassados serem insuficientes para arcar com profissionais específicos para as diferentes atribuições. Logo, as ações de vigilância não são desenvolvidas, e os gestores se detêm em procedimentos curativos, fortalecendo na população a compreensão de que as necessidades em saúde se concentram em sua maioria nos hospitais e no corpo médico, ou seja, na recuperação. 
CARDOSO, A. F.; COSTA, V. A. M.; SILVA, C. A.

A importância do território em ações de vigilância em saúde

[...] os usuários buscam nos serviços de saúde respostas às queixas de ordem clínica.

Não se revela, portanto, uma conexão imediata entre as 'necessidades de saúde' e a peculiaridade de sua inserção na sociedade. [...] as pessoas compreendem mais concretamente a dimensão biológica do processo saúde-doença e não associam às questões sociais que atuam de forma a fortalecer ou desgastar o processo de vida. (MORAES; BERTOLOZZI; HINO, 2011, p. 22).

Por esse motivo, os parâmetros de atendimento em saúde devem estar articulados com a ampliação do direito de cidadania, com as políticas econômicas e sociais para a promoção e vigilância em saúde. Sendo válido considerar uma reformulação dos serviços de saúde, onde todos os servidores de saúde local, também se reconheçam como agentes de vigilância para identificar na população do seu território os possíveis riscos à saúde, buscando formas de combatê-lo.

Desse modo, a utilização do território é de grande importância para a operacionalização de diferentes situações no campo da saúde, como a busca de estratégias para vigiar, controlar, prevenir riscos e agravos à saúde na população em diferentes escalas territoriais, isto é, todo sistema de saúde, em nível estadual, municipal, da região, do bairro, devem se estruturar para dar cobertura efetiva em serviços de saúde (PAIM,1994) como aponta a (figura1):

Figura 1: Processos que envolvem o território em vigilância de saúde

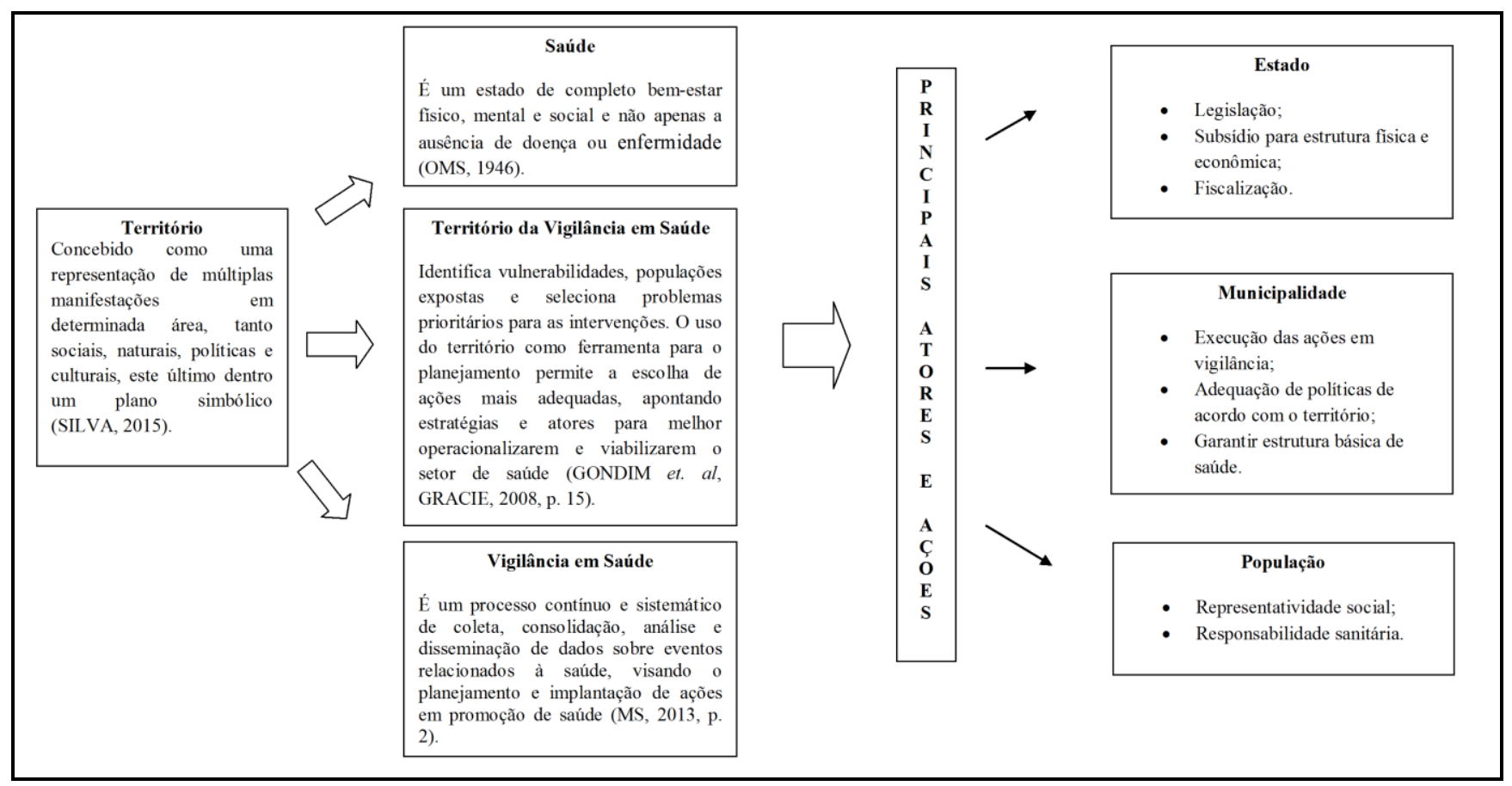

Fonte: COSTA, 2019; CARDOSO, 2019.

Revista Cerrados, Montes Claros/MG, v. 18, n. 2, p. 50-68, jul./dez.-2020. 
CARDOSO, A. F.; COSTA, V. A. M.; SILVA, C. A.

A importância do território em ações de vigilância em saúde

A figura "Processos que envolvem o território em vigilância e saúde", parte da perspectiva que o território é um instrumento de gestão efetivo em distintas áreas, na saúde especificamente, reduz desigualdades, proporciona acesso à saúde, melhor atendimento, políticas eficazes e estrutura básica. As interfaces desse processo se revelam a partir da atuação política nas esferas federal, estadual e local, bem como social, que são responsáveis por legislar, fiscalizar, adequar às políticas de acordo com as demandas do território, e a população cabe necessariamente à responsabilidade e os cuidados sanitários.

O processo de território e saúde tratado aqui, não diz respeito a criar territórios de serviços de saúde, mas adaptá-los à realidade social (FARIA, 2013). As estratégias de planejamento, no caso referente à vigilância e ao acesso a saúde, devem ser institucionalizadas sobre uma estrutura material e imaterial já existente. Dentre os agentes mencionados acima, é válida a reflexão sobre o papel do Estado, que historicamente, em resposta às demandas sociais, priorizando o bem estar, oferta o sistema de saúde universal, gratuito e participativo, mas que por muito tempo esteve centralizado. Pessoto et. al. (2015) criticam a

[...] dificuldade de articulação entre as diferentes esferas de poder - municipal, estadual e federal - fruto da ausência de um pacto federativo efetivo na república brasileira, desde a sua gênese. Em determinados períodos da história da saúde pública no país observa-se um processo de concentração na esfera central e a presença e o controle das instituições estatais sobre o território a partir do centro (PESSOTO; RIBEIRO; GUIMARAES, 2015, p. 17).

Desta forma, valoriza-se a municipalização, pois é através da descentralização que estratégias e políticas de universalidade, equidade, integralidade propostos na Constituição Federal são garantidos ao cidadão. Seguindo estas perspectivas, os autores citados nesta parte entendem que a centralização fez parte da história, no entanto, as inovações do sistema de saúde pública no Brasil há muito a se fazer, ao se considerar o lugar onde as pessoas vivem, circulam e trabalham como lócus para a definição das prioridades de saúde. Neste sentindo a implantação de políticas voltadas para as particularidades dos territórios seria uma ação imprescindível para a garantia de saúde. 
CARDOSO, A. F.; COSTA, V. A. M.; SILVA, C. A.

A importância do território em ações de vigilância em saúde

\section{CONSIDERAÇÕES FINAIS}

Ao longo do desenvolvimento da ciência geográfica, identifica-se que a categoria território norteou diversos estudos e foi modelada em função dos modos de produção e das relações humanas contidas no espaço. A partir das contribuições de diversos pesquisadores o território foi agregando a multiplicidade de processos possuindo dupla conotação, material e simbólica, o que proporcionou aplicações e análises em vários ramos científicos.

No campo da saúde o território é imprescindível para a criação e manutenção dos serviços, uma vez que estrutura a rede pautada nas particularidades de um povo em determinada porção territorial. Portanto, é possível identificar vulnerabilidades, grupos sociais expostos aos riscos e ambientes insalubres.

De forma geral, o setor de saúde carece de perspectiva estratégica, teórica e política que incorpore o território nas diversas escalas, para refletir além do viés administrativo e oferecer condições de acesso aos serviços básicos. Todavia, sabe-se que esse fator depende também dos incentivos da esfera federal de governo, principalmente provendo os recursos. Os territórios da vigilância em saúde são caracterizados como ferramentas de planejamento para auxiliar no processo local de identificação de vulnerabilidades e necessidades da população para atuar sobre elas.

A aplicação das ações de atenção primária, em especial da vigilância em saúde fomenta o contado direto das instituições com os indivíduos, permitindo um diagnóstico mais preciso acerca dos processos que influenciam e modelam o cotidiano da sociedade, bem como o mapeamento dos percursos e interações com outros espaços.

Ações de atenção primária são dirigidas às populações em territórios préestabelecidos, para isso o trabalho das equipes é definido em consonância com as UBS, que são elencadas e programadas programam atividades de acordo com as demandas de cada território, priorizando as intervenções clínicas e sanitárias segundo critérios de frequência, risco, vulnerabilidade, resiliência.

Portanto, a categorização do território é uma estratégia/ferramenta essencial para ações em vigilância, bem como subsídio para as políticas de saúde que devem fundamentar-se nas particularidades dos processos do território, uma vez que somente os aspectos biológicos não são suficientes para a organização do sistema de atenção à saúde que realmente atenda as particularidades da população. 


\section{AGRADECIMENTOS}

Agradecimentos à Coordenação de Aperfeiçoamento de Pessoal de Nível Superior - CAPES pelo apoio financeiro.

\section{REFERÊNCIAS}

AERTS, D.; ALVES, G. G.; LA SALVIA, M. W.; ABEGG, C. Promoção de saúde: a convergência entre as propostas da vigilância da saúde e da escola cidadã. Cad. Saúde Pública, Rio de Janeiro, v.20, n.4, pp.1020-1028, Jul - Ago, 2004.

ALMEIDA, M. G. Festas rurais e turismo em territórios emergentes. Bibliográfica de Geografía y Ciencias Sociales, Barcelona, v. 15, n. 918, S/P, 2011. Disponível em: <http://www.ub.edu/geocrit/b3w-919.htm >. Acesso: 15 de Novembro de 2018.

ARREAZA, A. L. V.; MORAES, J. C. Vigilância da saúde: fundamentos, interfaces e tendências. Ciênc. saúde coletiva [online], Rio de Janeiro, v.15, n.4, pp. 2215-2228, Julho, 2010. Disponível em: $<$ http://www.scielo.br/scielo.php?script=sci_arttext\&pid=S141381232010000400036>. Acesso: 19 de Novembro de 2018.

BRASIL. Ministério da Saúde. Secretaria de Vigilância em Saúde. Diretrizes para a integração entre atenção básica e vigilância em saúde. Brasília: Ministério da Saúde, 2009. 13p. Disponível em< https://www.nescon.medicina.ufmg.br/biblioteca/imagem/3317.pdf > Acesso: 19 de Novembro de 2018.

BRASIL. Ministério da Saúde - MS. LEI N 8.080, DE 19 DE SETEMBRO DE 1990. Dispõe sobre as condições para a promoção, proteção e recuperação da saúde, a organização e o funcionamento dos serviços correspondentes e dá outras providências. Disponível em:< http://www.planalto.gov.br/ccivil_03/leis/18080.htm>. Acesso: 17 de Mai. 2019.

BRASIL. Ministério da Saúde. Portaria GM/MS no 1.679, de 19 de setembro de 2002. Dispõe sobre a estruturação da rede nacional de atenção integral à saúde do trabalhador no SUS e dá outras providências. Disponível em:< http://ftp.medicina.ufmg.br/osat/legislacao/Portaria_1679_12092014.pdf $>$. Acesso em: 21 de Mai. 2019.

BRASIL. Ministério da Saúde. Secretaria Executiva. Departamento de Apoio à Descentralização. Coordenação-Geral de Apoio à Gestão Descentralizada. Diretrizes operacionais dos Pactos pela Vida, em Defesa do SUS e de Gestão. Brasília: Editora MS, 2006.

BRASIL. Ministério da Saúde. Secretaria de Políticas de Saúde. Departamento de Atenção Básica. Área Técnica de Saúde do trabalhador. Saúde do trabalhador - Cadernos de Atenção Básica n. 5. Brasília: Editora MS, 2001. 
BRASIL. Ministério da Saúde - MS. Portaria n 1.378, de 9 de Julho de 2013. Brasília: Editora MS, 2013. Disponível em:

<http://bvsms.saude.gov.br/bvs/saudelegis/gm/2013/prt1378_09_07_2013.html>. Acesso: 14 de Novembro de 2018.

CARVALHO H. M. Os territórios da saúde e a saúde dos territórios: discutindo o processo de territorialização em saúde a partir do caso de um serviço de atenção primária em Porto Alegre/RS. 2003. 155 f. Dissertação (Mestrado em Administração) - Universidade Federal do Rio Grande do Sul, Porto Alegre - RS, 2003.

CASTELLANOS, P. L. On the concept of health and disease. Description and explanation of the health situation. Epidemiol Bull, Pennsylvania, v.10, n.1-8, S/P, Jan. 1990. Disponível em:< https://plato.stanford.edu/entries/health-disease/>. Acesso: 15 de Novembro de 2018.

COLIN, E. C. S.; PELICIONI, M. C. F. Territorialidade e promoção da saúde: quando a gestão participativa faz a diferença. In: II Simpósio Brasileiro de Saúde e Ambiente. Belo Horizonte. Anais do II Simpósio Brasileiro de Saúde e Ambiente. Belo Horizonte: ABRASCO, 2014. S/P. Disponível em:<http://www.sibsa.com.br/resources/anais/4/1403114962_ARQUIVO_ResumoElaineeCe cilia-simpMG2.pdf >. Acesso: 14/09/2018.

CONASS - Conselho Nacional de Secretários de Saúde. Para entender a gestão do SUS Progestores. Brasília: CONASS, 2015.

CZERESNIA, D.; RIBEIRO, A. M. O conceito de espaço em epidemiologia: uma interpretação histórica e epistemológica. Cad. Saúde Pública, Rio de Janeiro, v. 16 n. 3: pp. 595-617, 2000.

DEMATTEIS G. Sistema Local Territorial: um instrumento para representar, ler e transformar o território. In: ALVES, A. F.; CORRIJO, B. R.; CANDIONOTTO, Z. P. (Org.). Desenvolvimento territorial e agroecologia. São Paulo: Expressão popular, 2008. p. 33-44.

DUTRA, D. A. Geografia Da Saúde No Brasil: Arcabouço téorico-epistemológicos, temáticas e desafios. 2011. 191 f. Tese (Doutorado em Geografia), Programa de PósGraduação em Geografia, Universidade Federal do Paraná - UFPR, Curitiba, 2011.

FARIA, R. Os desiguais limites da porta de entrada do Sistema Único de Saúde (SUS) em Pouso Alegre, Minas Gerais, Brasil. Ra'eGa: O Espaço Geográfico em Análise, Curitiba, v. 29, p. 135-156, 2013.

FERNANDEZ, J. C. A. Determinantes culturais da saúde: uma abordagem para a promoção de equidade. Saúde Soc., São Paulo, v. 23, n.1, p.167-179, 2014.

GOLDSTEIN R. A.; BARCELLOS C. Geoprocessamento e Participação Social: ferramentas para a vigilância ambiental em saúde In: Território, Ambiente e Saúde. Rio de Janeiro: Editora Fiocruz; 2008. 
GONDIN, G. M. et al. O território da saúde: A organização do sistema de saúde e a territorialização. In: BARCELLOS, C. et. al. (Org.). Território, ambiente e saúde. Rio de Janeiro: Editora Fiocruz, 2008, p. 237-255.

GUIMARÃES, R. B. Saúde: fundamentos de Geografia humana [online]. São Paulo: Editora UNESP, 2015.

GUIMARÃES, R. B.; PICKENHAYM, J. A.; LIMA, S. C. Geografia e Saúde: Sem fronteiras. Uberlândia: Editora Assis, 2014.

GUIMARÃES, R.B. Geografia e saúde. In: Saúde: fundamentos de Geografia humana [online]. São Paulo: Editora UNESP, 2015, p. 17-39.

HAESBAERT, R. O mito da desterritorialização 1958. In: Do "fim dos territórios" à Multiterritorialidade. Rio de Janeiro: Bertrand Brasil, 2004.

ITABORAHY, Nathan Zanzoni. A geografia, o conceito do território e os processos de territorialização das comunidades quilombolas: primeiras aproximações. In: XVI Encontro Nacional de Geógrafos. Anais do ENG - Encontro Nacional de Geógrafos. Porto Alegre: Associação dos Geógrafos Brasileiros - AGB, 2010. S/P. Disponível em: < https://www.agb.org.br/xvieng/anais/index.html >. Acesso: 15 de Novembro de 2018.

LIMA, L.; SILVA, L. X.; FORNO, M. A. R. Dal. A Evolução Histórica dos Conceitos de Território/Territorialidade no Contexto do Desenvolvimento Rural. Caderno de Estudos Interdisciplinares, Alfenas, v.1, n.1, p. 1 - 11. Março, 2014. Disponível em <https://cadernodeestudosinterdisciplinares.com.br>. Acesso: 14 de Novembro de 2018.

MENDONÇA, F.; ARAÚJO, W. M.; FOGAÇA, T. K. A geografia da saúde no Brasil: Estado da arte e alguns desafios. Revista Investig. Geogr. Chile, [S./l.], v. 48, p. 41-52, 2014. Disponível em: < www.investigacionesgeograficas.uchile.cl/index.php/IG/article/download/.../38269>. Acesso: $11 / 09 / 2017$.

MONKEN, M.; BARCELLOS, C. Vigilância em saúde e território utilizado: possibilidades teóricas e metodológicas. Cad. Saúde Pública, Rio de Janeiro, v. 21, n. 3, p. 898-906, Mai Jun, 2005. Disponível em:

$<$ https://www.scielosp.org/scielo.php?pid=S0102311X2005000300024\&script=sci_arttext\&tl ng=pt $>$. Acesso: 14 de Novembro de 2018.

MORAES, P. A.; BERTOLOZZI, M. R.; HINO, P. Percepções sobre necessidades de saúde na Atenção Básica segundo usuários de um serviço de saúde. Revista Escola Enfermagem USP, São Paulo, v. 1, n. 45, p.19-25, 2011. Disponível em: <http://www.scielo.br/pdf/reeusp/v45n1/03.pdf>. Acesso em: 21 de Maio de 2019.

NETTO, G. F. et al. Vigilância em Saúde brasileira: reflexões e contribuição ao debate da 1a Conferência Nacional de Vigilância em Saúde. Ciênc. saúde coletiva [online], [S./l.], v. 22, 
n.10, p. 3137-3148, 2017. http://www.scielo.br/pdf/csc/v22n10/1413-8123-csc-22-103137.pdf>. Acesso: 20 de Novembro de 2018.

Organização Mundial de Saúde- OMS. Constituição da Organização Mundial da Saúde (OMS/WHO) - 1946. Nova Iorque em 22 de Julho de 1946. Disponível em:< http://www.direitoshumanos.usp.br/index.php/OMS-Organiza\%C3\%A7\%C3\%A3o-Mundialda-Sa\%C3\%BAde/constituicao-da-organizacao-mundial-da-saude-omswho.html>. Acesso: 08/02/2019.

PAIM, J. S. Recursos humanos em saúde no Brasil: problemas crônicos e desafios agudos. São Paulo: Faculdade de Saúde Pública - Universidade de São Paulo, 1994.

PEREHOUSKEI, N. A.; BENADUCE, G. M. C. Geografia da saúde e as concepções sobre o território. Revista Gestão \& Regionalidade, São Paulo, v. 23, n. 68, Set - Dez/2007.

Disponível em:< http://seer.uscs.edu.br/index.php/revista_gestao/article/view/78/39>. Acesso: $11 / 09 / 2017$.

PESSOTO, U. C.; RIBEIRO, E. A. W.; GUIMARÃES, R. B. O papel do Estado nas políticas públicas de saúde: um panorama sobre o debate do conceito de Estado e o caso brasileiro. Saúde Soc., São Paulo, v. 24, n.1, p. 9-22, 2015.

RAFFESTIN, C. Por uma geografia do poder. São Paulo: Editora Ática, 1993.

RATZEL, F. Geografia do homem (Antropogeografia). In: MORAES, Antônio Carlos Robert de (Org.). Ratzel. São Paulo: Ática, 1990. p. 33-107.

RECKTENWALDT, M.; JUNGES, J. R.. A organização e a prática da Vigilância em Saúde em municípios de pequeno porte. Saúde Soc., São Paulo, v. 26, n.2, p.367-381, 2017. Disponível em:< http://www.scielo.br/pdf/sausoc/v26n2/1984-0470-sausoc-26-02-00367.pdf >. Acesso: 23 de Novembro de 2018.

SACK, R. Human Territoriality. Cambridge: Cambridge University Press, 1986.

SAQUET, Marcos Aurélio. Abordagens e concepções de território. São Paulo: Expressão Popular, 2007.

SANTOS, M. Por uma outra globalização: do pensamento único à consciência universal. Rio de Janeiro: $6^{\circ}$ Ed. Record, 2003.

SILVA, L. A. A vigilância permanente da saúde e o método epidemiológico. Rev. Saúde pública, Florianópolis, v. 1, n. 1, Jan.- Jun. 2008. Disponível em:<http://www.dive.sc.gov.br/conteudos/publicacoes/livros_artigos/Artigo_Revista_SPSC.p df >. Acesso: 14 de Novembro de 2018.

SILVA, P. A. S. Território: abordagens e concepções. Boletim DATALUTA, São Paulo, n. 96, Dez. 2015. Disponível em: 
<http://www2.fct.unesp.br/nera/artigodomes/12artigodomes_2015.pdf>>. Acesso: 15 de Novembro de 2018.

SOUZA, M. J. L. O território: sobre espaço e poder, autonomia e desenvolvimento. In: CASTRO, I. E.; GOMES, P. C. C.; CORRÊA, R. L. (Org.). Geografia: Conceitos e temas. $8^{\mathrm{a}}$ ed. - Rio de Janeiro: Bertrand Brasil, 2006.

STÜRMER, A. B.; COSTA, B. P.. Território: aproximações a um conceito-chave da geografia. Revista Geografia, Ensino \& Pesquisa, Santa Maria, V. 21, n.3, p. 50-60. 2017.

THACKER, S. B.; BERKELMAN, R. L. Public health surveillance in the United States. Revista Epidemiologic Reviews. Oxford: Ed. Oxford, 1988.

\section{Autores}

Aline Fernanda Cardoso - É Graduada e Mestre em Geografia pela Universidade Estadual de Montes Claros (UNIMONTES).

Valéria Aparecida Moreira Costa - É Graduada e Mestre em Geografia pela Universidade Estadual de Montes Claros (UNIMONTES). Atualmente é Professora na Secretaria Estadual de Educação de Minas Gerais.

Cássio Alexandre da Silva - É Graduado em Geografia e Mestre em Desenvolvimento Social pela Universidade Estadual de Montes Claros (UNIMONTES), e Doutor em Geografia pela Universidade Federal de Uberlândia (UFU). Atualmente é Professor do Programa de Pós-Graduação em Geografia - PPGEO e do Departamento de Geociências da Universidade Estadual de Montes Claros (UNIMONTES).

Artigo recebido em: 19 de fevereiro de 2020.

Artigo aceito em: 29 de junho de 2020.

Artigo publicado em: 01 de julho de 2020. 